\title{
Study on the Evaluation of the Balance System between Cultivated Land Occupation and Compensation
}

\author{
Guo Yukun \\ SWUN \\ Chengdu, China \\ 77528934@qq.com
}

\author{
Wang Jiayi \\ SWUN \\ Chengdu, China \\ cissyfannn@163.com
}

\begin{abstract}
As a basic system in China, balance system between cultivated land occupation and compensation exposed some problems in the implementation which needs to be improved. In view of its implement effects, the paper uses methods of comprehensive analysis, field survey, statistical analysis and case analysis to analyze the necessity and feasibility adjusting the balance system of cultivated land occupation and compensation basing on evaluating the system. The results show the current compensation system is great successful, but the distribution of the cultivated land reserve resources is uneven, it is difficult to verify the quantity of add supplementary cultivated land, the quality of the add land is not high. It concludes that the adjustment of the balance system of cultivated land occupation and compensation is essential and fe asible.
\end{abstract}

Keywords-balance between cultivated land occupation and compensation; effectiveness; land value compensation; evaluation

As a basic system in China, balance system between cultivated land occupation and compensation plays a vital role in cultivated land protection, new rural construction and so on [1-2]. But it exposed some problems in the implementation which needs to be improved [3-4]. Based on the analysis of Chinese balance system between cultivated land occupation and compensation the essay evaluates the implement effects, analyze the dilemma and causes, and propose the necessity and feasibility of current policies' adjustment.

\section{Situation of Balance OF OCCUPATION AND COMPENSATION BETWEEN CULTIVATED LANDS}

\section{A. The Cultivated Land Occupied by Construction}

According to China Land Resources Statistical Yearbook 1999-2012, the national cultivated land occupied by construction is 3,055,200 hectares, which is less than the added supplementary cultivated lands for land arrangement and reclamation (as seen in Fig. 1). As seen in Fig. 1, the cultivated lands occupied by construction in 2004 ranked the priority, which is 293,000 hectares. 2000 owned the least areas of 163,300 hectares.

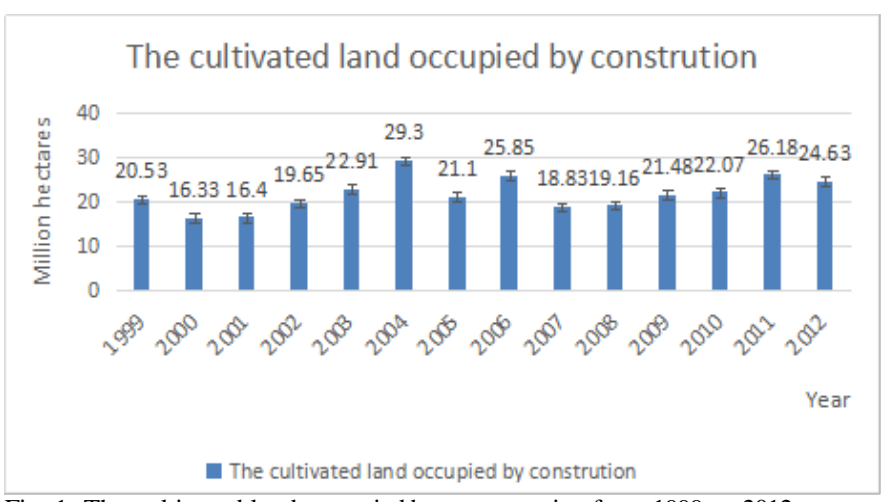

Fig. 1. The cultivated land occupied by construction from 1999 to 2012

\section{B. Land Development and Arrangement for Adding} Farmlands

According to China Land Resources Statistical Yearbook 1999-2012, during 1999 and 2012, China added 4,178,800 hectares by land arrangement and reclamation (as seen in Fig.2.). As seen in Fig. 2, the most lands happened in 2012, which is 418,600 hectares and the least is in 2007, which is 195,800 hectares.

The supplementary of cultivated land

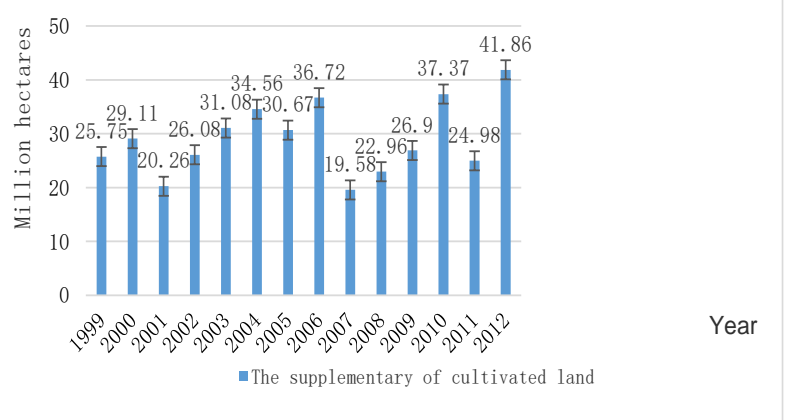

Fig. 2. The supplementary of cultivated land by land consolidation from 1999 to 2012 


\section{Cultivated Land Occupation and Compensation}

Based on Table 1 raised by Ministry of Land and Resources of the People's Republic of China, during 1999 and 2012, area of national cultivated lands realizes the balance of occupation and compensation in terms of quantity and the added supplementary cultivated lands is obviously more than the cultivated lands occupied by construction During 1999 and 2012, national cultivated lands occupied by construction is totally 3,055,200 hectares and the added supplementary cultivated lands for land arrangement and reclamation is $4,178,800$ hectares. The compensation is $1,123,600$ hectares more than occupation, 80,300 hectares' decrease annually.

TABLE I. THE IMPLEMENT ATION DAT A OF CULTIVATED LAND

\begin{tabular}{|c|c|c|c|}
\hline Year & $\begin{array}{c}\text { Added supplementary } \\
\text { Cultivated Land }\end{array}$ & $\begin{array}{c}\text { Cultivated Land } \\
\text { Occupied by } \\
\text { Construction }\end{array}$ & $\begin{array}{c}\text { Balance of Occupation } \\
\text { and Compensation }\end{array}$ \\
\hline 1999 & 25.75 & 20.53 & 5.22 \\
\hline 2000 & 29.11 & 16.33 & 12.78 \\
\hline 2001 & 20.26 & 16.4 & 3.86 \\
\hline 2002 & 26.08 & 19.65 & 6.43 \\
\hline 2003 & 31.08 & 22.91 & 8.17 \\
\hline 2004 & 34.56 & 29.3 & 5.26 \\
\hline 2005 & 30.67 & 21.2 & 9.47 \\
\hline 2006 & 36.72 & 25.85 & 10.87 \\
\hline 2007 & 19.58 & 18.83 & 3.75 \\
\hline 2008 & 22.96 & 19.16 & 5.22 \\
\hline 2009 & 26.9 & 21.68 & 14.5 \\
\hline 2010 & 37.37 & 22.87 & 8.8 \\
\hline 2011 & 34.98 & 26.18 & 17.23 \\
\hline 2012 & 41.86 & 24.63 & 112.36 \\
\hline Total & 417.88 & 305.52 & \\
\hline & & Note: china land resources statistical yearbook $1999-2013$ \\
\hline
\end{tabular}

\section{ACHIEVEMENTS OF BALANCE OF OCCUPATION AND COMPENSATION BETWEEN CULTIVATED LANDS}

\section{A. Insure Red Line and Food Safety}

During 1999 and 2012, the cultivated land occupied by construction is 3,055,200 hectares. Until the end of 2012, national stocks of cultivated lands was 2.27 billion mu (nearly 135 million hectare) which was over the red line of cultivated land (1.8 billion $\mathrm{mu}$ ) and was also over targeted national stocks of cultivated land of 1.818 billion mu until 2010 which was proposed by Overall Plan of National Land 2006-2020. Balance of occupation and compensation between cultivated lands guarantees the food safety and the red line of 1.8 billion mu. During 2004 and 2013, national food production has been increasing for 10 years and the comprehensive production keeps over 500 million ton which guarantee people's consumption and social and economic development as well as insure national food safety.

\section{B. Introduce Expansion of Construction-used Land in Order and Realize the Sustainable Development of Economy and Society}

Macro-control of land is to control the aggregate demand and supply of land and lands for all kind of use as well as the distribution of land interest. Although the balance of occupation and compensation between cultivated lands will not participate in the control of demand and supply directly, however, as a kind of tightening protectionism in cultivated land with, it realizes the stable and healthy development of society and economy. Compensation first and occupation second will contain the disorderly expansion of constructionused land radically and ensure the stable and healthy development of the land industry.

\section{Improve Ecological Environment and the Construction of Ecology}

The balance of occupation and compensation projects insists "protection and development proceed at the same pace". The scientific implementation and professional construction realize the ecological interest. Through relative projects, overall improvement of cultivated lands, water, road, forest and village in the project area and the mating infrastructure, the following factors are improved: agriculture production condition, ecological environment, soil and water loss, agriculture environment and climate and ecological construction.

\section{Enhance Agriculture Industry and Increase Farmers' Income}

Through balance of occupation and compensation between cultivated land, China practices a large quantity of land arrangement projects, realizing urbanization and new rural construction. Though arrangement of cultivated lands, cultivated lands realize concentrated and flat land with mating facilities and convenient transportation, which provides chance for professional business as well as development of agriculture industry. Meanwhile, the implementation will further enhance production and maintain food production as well as improve farmers' income.

\section{E. Optimize Land Structure and Push Overall Development between Urban and Rural Areas}

Through balance of compensation and occupation between cultivated lands, China implements land arrangement projects like cultivated lands arrangement, plus and Minus Hook in construction-used land and land development. By these projects, urban cities develop rapidly and rural dwelling is more centralized. The cultivated lands are centralized which optimizes the land structure. The arrangement also promotes rural investment and consumption demand as well as the communication between rural and urban areas which push forward the overall development of rural and urban areas.

\section{The Major Difficulty and Problem in Balance of COMPENSATION AND OCCUPATION BETWEEN CULTIVATED LANDS}

\section{A. Unbalanced Distribution of Cultivated Lands}

Because of the unbalanced distribution, some areas are difficult to realize balance of occupation and compensation between cultivated lands. According to Plan of national land arrangement 2011-2015, the potential added supplementary cultivated lands are 10.5 million hectares. Among that, 4.2 million hectares are located in Northwest, Northeast and Southwest areas. The potential added supplementary cultivated lands for development are 2.7 million hectares which mostly distribute in west regions with large resources. The potential added supplementary cultivated lands for reclamation are 3.6 
million hectares which mostly are located in Shanxi, Inner Mongolia with intensive coal resources.

\section{B. Difficult Check of Added Supplementary Cultivated Lands}

Currently, there are some problems, like incorrect quantity of land arrangement and the difficult verification of new cultivated land, in some land arrangement projects. Chengdu Bureau of State land Supervision found that during the Eleventh Five-Year Plan in Chongqing, Sichuan and Yunnan, the newly added false projects of added supplementary cultivated lands are 43 and the false areas of cultivated lands are 3,162.51 mus. Besides, most area quantity of added supplementary cultivated lands for arrangement is out of Ridge Coefficient, which is common across the country[5]

\section{Poor Quality of Added Supplementary Cultivated Lands}

From the perspective of national cultivated lands, the added supplementary cultivated lands are in balance but the quality is poor. The projects of balance of occupation and compensation in some areas occupy better lands and compensate worse lands as well as occupy nearer lands and compensate farther lands. The construction-used lands occupy the cultivated lands in rural-urban fringe zone with high quality while the supplementary cultivated lands are located in the far area or areas with inconvenient transportation or areas with fragile cultivated eco-system or areas with ecological obstacles. The cultivated lands have poor conditions. The irrigation is unsatisfactory. There lacks corresponding staff ploughing. The production is relatively low in danger of uncultivated lands.

\section{Unprofessional Land Arrangement and Management}

Firstly, does not have overall plan and scientific design. In China, the current overall plan of land use, arrangement and management is far behind the practical needs which do not satisfy the development needs of social and economic development in the planned regions. Meanwhile, the comprehensive plan of land arrangement and management is hard to connect with special plans, like irrigation and water conservancy, industry development of agriculture and new rural construction.

Secondly, the current plan ignores ecological environment and lacks evaluation system. In order to realize the task of occupation and compensation between cultivated lands, in the process of land arrangement and management, some areas think less on ecological environment which results in serious consequence.

Furthermore, there lacks effective supervision without fully respecting farmers' wills. Now, the whole process of implementing occupation and compensation projects are all managed and operated by the government without social supervision. It is easy give rise to corruption. Besides, in order to meet the deadline, some projects force to proceed without respecting farmers' wills and interests. Farmers' resistance disturbs implementation which not only affects the implementation of balance of occupation and compensation between cultivated lands but also causes serious social influence[6].

\section{E. Waste Caused by Duplicate Arrangement and Unreasonable Maintain of Supplementary Cultivated Lands}

The duplicated arrangement includes two conditions. The first is the land arrangement is same or partly same with projects led by Ministry of Agriculture, Water Resources, Finance and Tobacco. The second is that the lands become uncultivated after the project and local government set it as the new project which results in the waste of human, material and financial resources. Because the lagged information construction of land, many duplicate projects are hard to detect.

After the projects of land arrangement, some areas did not fertilize cultivated lands, which result in ditch blockage, road damage, water leak and rusty water gate. All these affect the performance of supplementary cultivated lands.

\section{F. Hard to Carry out Balance of Occupation and Compensation in National Major Projects}

The major aspect of cultivated land occupied by construction is national major project, which is also the difficulty in supplementary cultivated lands.

Firstly, it occupies a large quantity of areas especially occupying a large quantity of cultivated lands and lack of funds. The funds for supplementary cultivated lands do not include in the project budget. The funds for reclamation are hard to carry out.

Secondly, the responsibility and right of occupation and compensation between cultivated lands are unclear which concern many bodies with complex interest management. It is hard to carry out the supplementary cultivated lands which result in the situation that some project units compensate cultivated lands while proceed projects or even after completing the project, supplementary cultivated lands are not in place.

Thirdly, the related provinces and cities have totally different structure in industry and agriculture, economic fourthly, the encourage mechanism of land arrangement has not been formed. Provincial departments of land and resources take responsibilities of the balance of occupation and compensation from national and provincial major projects which reduce the enthusiasm of local land development and arrangement.

Fifthly, the examination of land development and arrangement is complex with high standard which may results in low efficiency of project implementation.

Sixthly, some local governments offer all kinds of flavors in order to get the project and ignore the supplementary cultivated lands.

\section{REASONS}

\section{A. Unmatched System Requirements with Development Situation}

The system of occupation and compensation between cultivated lands is a legal system. However, in fact, the supplementary cultivated lands and the occupied cultivated 
lands cannot achieve balance. The unmatched situations of system requirements with development show in the following three aspects.

First, the longtime rapid advance in economy consumes cultivated lands a lot. However, the conflict of supplementary cultivated lands is outstanding because of the poor supplementary cultivated lands, far distribution and long period of forming cultivated lands.

Secondly, the population situation, farmers' cultivation consciousness and market interest determine that all fine cultivated lands have been used. The uncultivated lands do not possess the condition and potential for cultivation restricted by latitude, transportation, and fertility and cultivation interest.

Thirdly, under the pressure of the system and the more difficult supplementary, some local governments take the number balance as the top priority, playing falsification. In addition to that, it is hard to verify the quality of supplementary cultivated lands and it takes time to improve. The production of supplementary cultivated lands is totally below occupied cultivated lands.

\section{B. Unmatched Mating Policies and System Requirements}

Firstly, there exist no national unified methods of establishment, implementation, and examination for projects of land arrangement and reclamation. There is no unified system standard in the management of industry quality. There is no unified standard system for land arrangement and management which relies on industry standard of water resources and parting mapping.

Secondly, there are no quantitative criteria for the quality of supplementary cultivated lands. The current design of balance of occupation and compensation has not concerned the quality, which results in occupying the better one and compensating the worse one, like occupying paddy fields with compensating dry lands.

Thirdly, there is no clear specification for the planned location and all kinds of investment in the system. In addition to that, the unilateral pursuit for quantity balance separates the land arrangement, reclamation and development with large scale and less investment. The actual construction areas are small and the overall interest is not apparent.

Fourthly, there is no unified payment for reclamation, resulting in unreasonable payment management and unpaid situations.

Fifthly, the technology standard in the process of land development and arrangement does not meet the market requirements, especially the unit price of construction standard, material and manual work.

\section{Unmatched Supervision System and Current Situation}

Currently, there are many projects for land development, arrangement and management in the process of balance of occupation and compensation between cultivated lands across the country which lays more pressure on supervision of Ministry of Land Resources of People's Republic of China. It is difficult to supervise the reliability and truth for supplementary cultivated lands. Local departments of land resources play the role of executor and estimator in the management of supplementary cultivated lands which does not meet the requirements of modern management system and does ill to the cause of balance of occupation and compensation.

\section{Unmatched Team Construction and Development Requirements}

The policy of balance of occupation and compensation is closely related to professional technology. Because many projects supplementary cultivated lands are difficult and the basic security is weak, the current staff are not totally competent in daily management and security especially the professional talents of mapping, remote sensing and geographic information system which lays more pressure on the supervision of establishment, implementation and examination of the projects.

\section{Feasibility of Adjustment of the Current Policy}

On October 13th 2004, Decision of Deepening Land Reform and Being Strict with Land Management was published which marked that China would carry out the strictest land management system. On October 29th 2013, the third Plenary Session of the eighteen was held. In December, Decision of Deepening Reform in All Round Way by the Central Committee of the Communist Party of China, which clearly pointed out that the system of paid resources and the system of biological supplementary were adopted. These systems show that the protection system of cultivated lands is deepening and improving which desperately needs to improve the current system to adapt to the Five in One in the new situation.

The current balance system of occupation and compensation has achieved huge achievements. However, it has some problems, such as the lack of reserved resources, the incorrect number of supplementary cultivated lands, and difficulty in verifying new cultivated lands, damage to ecological environment. All the above problems need to adjust and improve the current balance system of occupation and compensation.

At the same time, with the improvement of balance of occupation and compensation in other cities, Plus and Minus Hook in urban and rural construction-used land and reclamation of factory and mining wasteland, the feasibility of adjusting balance system is more and more clear, plus the urgent need for industry, information and urbanization to agriculture modernization.

\section{CONCLUSION}

The current compensation system is great successful, but the distribution of the cultivated land reserve resources is uneven, it is difficult to verify the quantity of the added supplementary cultivated land, the quality of the add land is not high. So the adjustment of the balance system of cultivated land occupation and compensation is essential and feasible. 


\section{ACKNOWLEDGEMENTS}

This research was financially supported by National Philosophy and Social Science Foundation of China under Grant No.13XJY011, Graduate Programs Construction Foundation of Southwest University for Nationalities under Grant No. 2015XWD-S1204,2015XWD-S1202

\section{REFERENCES}

[1] Zhang Lin, Zhang Fengrong. Trend Forecast on Quantity of Balance of Occupation and Compensation between Cultivated Land in China[J]. Resources Science, 2007, 29(06) :114-119.(In Chinese)

[2] Xiao Bilin, Chen Yinjun, Chen Jing. The Situation and Feature of Current Balance of Occupation and Compensation in China[J]. Chinese Agricultural Science Bulletin, 2009, 25(08) : 299-302.(In Chinese)
[3] Zhang Fei, Zhang Aijun. Analysis of the Pros and Cons of Dynamic Balance of Cultivated Land in Different Provinces[J]. Journal of Anhui Agricultural Sciences, 2009, 37(17) :8116-8118.(In Chinese)

[4] Han Juan, Lv Juan, Xue Jian, Zhong Hexi. Problems and Suggestions of the Current Evaluation System of Balance of Occupation and Compensation between Cultivated Lands[J]. Resources and Industry, 2009, (01) :54-57.(In Chinese)

[5] The Bureau of Land and Resources Chengdu. The practice and Thin king of Trading Balance of Occupation and Compensation between Cultivated Lands in Chengdu[J]. Resources Environment Inhabitant, 2012, (11) :29-31.(In Chinese)

[6] Chen Yinjun, Xiao Bilin, Guo Jing xiang. The Analysis of Effect and Suggestion on Balance of Occupation and Compensation and Land Development and Arrangement[J]. Chinese Journal of Agricultural Resources and Regional Planning, 2010, 31(01):1-6.(In Chinese) 